\title{
External Environmental Analysis For Small And Medium Enterprises (SMEs)
}

\author{
Heather C. Banham, CGA, Okanagan College, Canada
}

\begin{abstract}
Small and Medium Enterprises (SMEs) face unique challenges in the business environment. SMEs need to successfully deal with the prevalent forces for change if they are to survive and grow and meet the expectations to create investment and employment opportunities. Successfully adapting to change from technological advances, customer expectations, supplier requirements, the regulatory environment and increasing competition requires successful implementation of organizational change. The 'Degrees of Turbulence' Model is proposed as a self assessment tool to aid SMEs in their environmental scan and to assist in assessing the potential impact and adjusting to the impending changes in the external environment to ensure continued viability.
\end{abstract}

Keywords: Small and Medium Enterprises, SMEs, strategic planning, business planning, viability, external environment, organizational change

\section{INTRODUCTION}

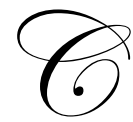

hallenges to the growth and viability of Small and Medium Enterprises (SMEs) are arising from globalization, increased customer expectations, technological advances, and increased competition. Business improvement models and process and management techniques have largely originated in large, private-sector organizations and are not necessarily applicable to SMEs. It is not considered appropriate for researchers to postulate that the planning and change processes of large organizations can be applied to SMEs in a less formal manner or on a smaller scale (McAdam, 2000; McAdam \& Armstrong, 2001; Curran \& Blackburn, 2001).

The purpose of this article is to present a tool designed to provide greater understanding of the impact of environmental changes specifically as they relate to SMEs. The 'Degrees of Turbulence' model is proposed to aid SMEs in the assessment of their environment therefore addressing an essential component of strategic planning. By providing a clearer picture of their current situation and a greater understanding of environmental risk, this model has the potential to assist SMEs with strategy formulation and revision.

Undertaking this research is justified on the basis of the following considerations. Firstly, there is a real lack of strategic analytical tools specifically relating to SMEs owing to the fact that most studies have been conducted in large organizations (McAdam, 2000). Secondly, globalisation and the pace of economic change are forces that are driving the need for a greater understanding of organizational change (Burke, 2002). Thirdly, there are high expectations for growth and performance of SMEs in the economic growth and development plans for Asia Pacific, Canada, British Columbia and the Okanagan region (Asia Pacific Economic Cooperation, 2002; Canadian Federation of Independent Business et al., 2002; Economic Development Commission, 2002). In order to survive and grow, SMEs need to be able to change and adapt as external challenges arise. Improved understanding of their operating environment can assist SMEs to meet the performance expectations of their owners and their respective governments.

\section{LITERATURE REVIEW}

The study of organizational change in SMEs, and specifically strategic planning as a tool for organizational change, spans two main areas. Firstly consideration has to be given to organizational change which is an emerging 
field. Many of the models for organizational change have been developed in the large business environment. Therefore there is a need for a greater understanding of SMEs as drivers of economic growth. The literature portrays SMEs as complex and quite different from large business specifically in relation to resources (McAdam, 2002; Freel, 2000; MacDougall\& Pike, 2004), markets (Todtling \& Kaufman, 2001; Chetty\& Campbell-Hunt, 2003); flexibility (Freel 2000; Cecora, 2000), leadership (McAdam, 2000; Fuller, 2003) and structure (McDonald \& Wiesner, 1997).

While the management and academic literature on the topic area of strategic planning has predominantly focused on the large business environment, there is now a growing body of knowledge related to the SME context. The link between strategic planning and small business success has been researched and documented (Meers \& Robertson, 2007) and the value and contribution from strategic planning for small firms is important (Beaver, 2007). Breaking down strategic intentions into actionable components and allocating responsibility for each of the components was considered an important part of successful implementation. In their empirical study of 267 firms, Joyce and Woods (2003) concluded that organizations using systems of strategic management made faster decisions and successfully implemented change and innovation to bring about growth. Even while acknowledging the importance of strategic and business planning, many small business owners and managers do not undertake the process, frequently citing lack of time, lack of familiarity with strategic management techniques and processes, lack of skills and confidence to begin the process, and lack of trust in internal stakeholders in relation to sharing business information as the reasons for non-implementation of strategic planning (Beaver, 2007).

Greater clarity is provided by Wang, Walker and Redmond (2007) where the owner's motivation for being in business, whether profit or growth maximization compared with personal fulfillment, was presented in their analysis of SMEs' engagement in strategic planning processes. Owner motivations are presented as a key determinant for engaging in strategic planning (Miller \& Toulouse (1986). Further, in investigating ownermanagers and the practice of strategic management it was determined that SMEs had access to fewer strategic tools than other managers, and as a consequence, used fewer tools in planning (Woods \& Joyce, 2003).

By their nature, SMEs have more limited human, material and financial resources (McAdam 2002; Vossen 1998 as cited in Huang, Soutar \& Brown, 2002). SMEs focus on allocation of resources to achieve their maximum short-term advantage, which frequently leaves them to respond to external influences as they occur rather than taking a proactive approach (McAdam, 2002). Hodges and Kent (2007) are clear in their direction to small business owners, "If you want to be more successful, then obtain more knowledge of the strategic planning process" (p.8). Analysis of the external environment is a crucial step in strategic planning whether utilizing critical success factor (CSF), 'what if' analysis, SWOT (strengths weaknesses, opportunities and threats), or stakeholder analysis. The assessment of external business conditions is considered essential to planning (Beaver, 2007). While the use of strategic management tools as an aid to business growth was confirmed, how managers in small firms handle strategic management in practice is still limited (Woods \& Joyce, 2003). Research has demonstrated lower levels of familiarity and lower levels of use of strategic tools by owner managers compared with other managers in small firms (Woods \& Joyce, 2003). The majority of small firms did not utilize the traditional tools and techniques of strategic planning in the study by Meers and Robertson (2007), yet their findings suggested that internal and external business condition assessments were worthy of consideration.

The number one question to ask in hard times is whether a strategic plan exists and it is communicated throughout the business organization (National Quality Institute, 2009). While the "research evidence points to the beneficial effects of planning on business performance" the way forward is suggested as taking a pragmatic approach including developing and using strategic planning tools (Woods \& Joyce, 2003, p 191).

Tools and models are used to bring clarity to complex issues; therefore, the 'Degrees of Turbulence' is presented as a model to assist owner/managers of SMEs in understanding the externalities that impact their business operations. A model should provide a useable and useful framework for categorizing the dimensions of an organization and enable planning, implementation and tracking of change to be more effective (Burke, 2002) and so it is postulated that SMEs have the opportunity to gain a greater understanding of their external environment if they are provided with appropriate tools that take into consideration the unique characteristics of those organizations. There is the need for the development of new tools to affect strategic change and that builds on the strengths of the 
essential contributions of leadership and teamwork according to Zeffane (1996). While SMEs were not discussed separately in this work, the literature reviewed is clear that SMEs are not just scaled-down versions of large enterprises. The 'Degrees of Turbulence' environmental assessment tool is presented to assist SMEs in the environmental analysis that is an essential component in strategic planning. It has been developed specifically for the small business environment which obviates the need for it to be scaled down or adapted to SMEs.

\section{FORCES FOR CHANGE}

The concept and content of the forces driving change in SMEs were investigated in relation to a larger project on organizational change (Banham 2005). These categories are included in the tool to assist SME owner/managers to consider present and emerging issues that will have an impact on their operations. In fact, these forces also related to the external opportunities and threats in the broad business environment that are normally considered as part of the SWOT analysis frequently forming a preliminary step in the strategic planning process. Table 1 presents a summary of the changes described in the literature and by SMEs and how they fit within the broad categories of technological advances, customer expectations, supplier requirements, regulatory changes and increasing competition with detailed explanations following.

Table 1 SME Change Drivers

\begin{tabular}{|c|c|}
\hline \multicolumn{2}{|c|}{ External Opportunities and Threats: } \\
\hline Technological Advances & $\begin{array}{ll}\text { - } & \text { Availability of New Technology } \\
\text { - } & \text { Affordability of New Technology }\end{array}$ \\
\hline Customer Expectations & $\begin{array}{ll}\text { - } & \text { Customer Expectations for Price } \\
\text { - } & \text { Customer Expectations for Quality } \\
\text { - } & \text { Changing Products or Services } \\
\end{array}$ \\
\hline Supplier Requirements & - $\quad$ Major Supplier Requirement \\
\hline Regulatory Changes & $\begin{array}{ll}\text { - } & \text { North American Free Trade Agreement (NAFTA) } \\
\text { - } & \text { Exchange Rate Fluctuations } \\
\text { - } & \text { Change in Government Regulation } \\
\end{array}$ \\
\hline Increasing Competition & $\begin{array}{ll}\text { - } & \text { Erosion of Profits } \\
\text { - } & \text { Increased Competition in marketplace } \\
\text { - } & \text { Export Market Opportunity } \\
\text { - } & \text { Desire to compete globally } \\
\end{array}$ \\
\hline
\end{tabular}

Source: Banham, 2005.

The availability and affordability of new technologies are a major component of the changes driven by technological advances. The customer expectation for price, quality and innovative products and services are components of the customer expectations that drive organizational changes. Supplier specifications fit within the supplier requirements category; and with moves towards just-in-time inventory and manufacturing requirements, there is an increasing need for SMEs to change to meet these expectations. Trade arrangements such as NAFTA, exchange rate fluctuations and change in government requirements are components of the external regulatory changes that drive SMEs to adapt and change. Finally, profit erosion, export market opportunities, desire to compete globally and low barriers to entry in many of the sectors where SMEs operate that are within the increasing competition category which forces SMEs to adapt and change in order to survive. The main external environmental triggers for change identified by Dawson (2001) were listed as government laws and regulations, globalization of markets and the internationalization of business, major political and social events, technological advancements, customer expectations, supplier requirements, increasing competition, organizational growth, and fluctuations in business cycles. These can also comfortably fit within the forces for change categories in the model. The turbulent conditions in the business environment are identified as being due to globalization, technology advancement, deregulation, emerging new markets and economic restructuring (Meers \& Robertson, 2007) and these are also accommodated within the five forces for change.

All of the specific examples of the events that initiated recent changes provided by the ten interviewed SMEs can be categorized into these forces for change (Banham, 2005). The forces for change are therefore 
considered to be validated as comprehensive categories and included in the 'Degrees of Turbulence' tool. The forces for change are always present in the environment of SMEs and the assessment tool has been designed to relate the SME to each aspect of the external environment. The change process begins with the external environment (Burke, 2002) and therefore, the starting point for the assessment is consideration of the external forces for change. If SME owner-managers review their external environment, they can better anticipate and plan for the impact on their business. The 'Degrees of Turbulence' tool is designed to assist them in that process.

The main external environmental triggers for change identified by Dawson (2001) were listed as government laws and regulations, globalization of markets and the internationalization of business, major political and social events, technological advancements, customer expectations, supplier requirements, increasing competition, organizational growth, and fluctuations in business cycles. These can also comfortably fit within the forces for change categories in the model. The changing demographics and the challenges to SMEs in attracting and retaining skilled workers was identified as their number one challenge in the Small Business Roundtable report (October, 2005). The recruitment and retention challenge is complex for small business and it is expected to continue over the long term. Demographic changes, specifically the aging workforce and the declining entrant pool, are occurring and while the economic cycle is currently countering some of the impact, the underlying demographic situation is here for the long-run. Early warning signs in the external environment are not always apparent to small business owners, so a challenge such as a major shift in the labour market can hit them with surprising force. As well, the multi-tasking responsibilities of small business owners and managers mean that they do not have the time to undertake research on this challenge or to read the research results of others.

The connection between survival and growth in SMEs and the adoption of explicit strategic planning has been documented (Perren, Berry \& Partridge, 1999 and Georgellis, Joyce \& Woods, 2000, each cited in Chan \& Foster, 2001). Progressive human resource management practices of selectivity in staffing, training and incentive compensation were found to be positively related to measures of organizational performance (Delaney \& Huselid, 1996) and in a study of critical success factors for small business, employee-relations factors, including training, involvement in decision making and a reward/discipline system were positively co-related to success in the service industry (Gadenne 1998).

Where a strategic plan was in place, leadership has been able to undertake proactively an appropriate response to the forces for change. SMEs without a plan only have the option of reaction. To do nothing would in most cases be an inappropriate response because depending on the strength of the force, an SME can become outdated due to a technological advance, lose its customers if it fails to meet their expectations, be unable to access raw materials and services if it ignores suppliers expectations, be subject to penalties if it does not respond to changes in the regulatory environment and incur losses if it does not continually build a competitive advantage in the face of increasing competition. The whole object of the tool is to assist SMEs in the process of understanding their external environment to enhance their ability to successfully negotiate of external change so that the SME can survive and grow. Monitoring the forces for change will enable SMEs to meet the challenges presented by those forces.

\section{'DEGREES OF TURBULENCE' ASSESSMENT TOOL}

SMEs need to scan the external business environment, and along with the knowledge of their industry make an assessment of the situation. There are four steps in the process and they are described in detail in this section.

\section{Step One: Assign a quantitative value to each of the 'Forces of Change'}

Consider each of the categories below and in regard to the number of changes extant in the environment assign a value based on your individual judgment.

Technological Advances Assign a value between 0 and 8 based on the number of technological advances in your operational area (two for each technological change up to a maximum of four changes). 
Customer Expectations Assign a value between 0 and 8 (two each for changed expectations in price, product features, delivery, and warranty/after sales service)

Supplier Requirements Assign a value between 0 and 8 based (assign four marks to each changed requirement that has been imposed on the SME by a major supplier)

Regulatory Environment Assign a value between 0 and 8 considering the number of regulations that have affected the SME in the past three years - examples include privacy legislation, environmental regulation, changed zoning, etc. (two for each change to a maximum of four changes)

Increasing Competition Assign a value between 0 and 8 based on your assessment of the competitive forces market entry of new competitors, availability of new substitutes, loss of distribution channels, strategic alliance formed by competitors, etc. (two for each competitive factor to a maximum of eight points).

\section{Step Two: Assess the Strength of the Force}

Consider each of the categories again and with particular regard to the number of changes extant in the environment assign a value. For example, a technological change that will impact processing of customer payments will have less force than a technological change that requires all new processing equipment. Assign a value between 1 and 9 to each of the forces for change. Base it on your assessment of the influence on the SME under consideration

Step Three: Multiply the value assigned to each force by the value assigned to its strength.

This is depicted in Figure 1 where each force for change is multiplied by the strength of the force to arrive at the 'Degrees of Turbulence' factor. There are five forces with a maximum score of eight (maximum value is 40) times nine for the strength of each force (maximum value of 360).

Figure 1 - Forces for Change multiplied by Strength of the Force equals the Degrees of Turbulence factor
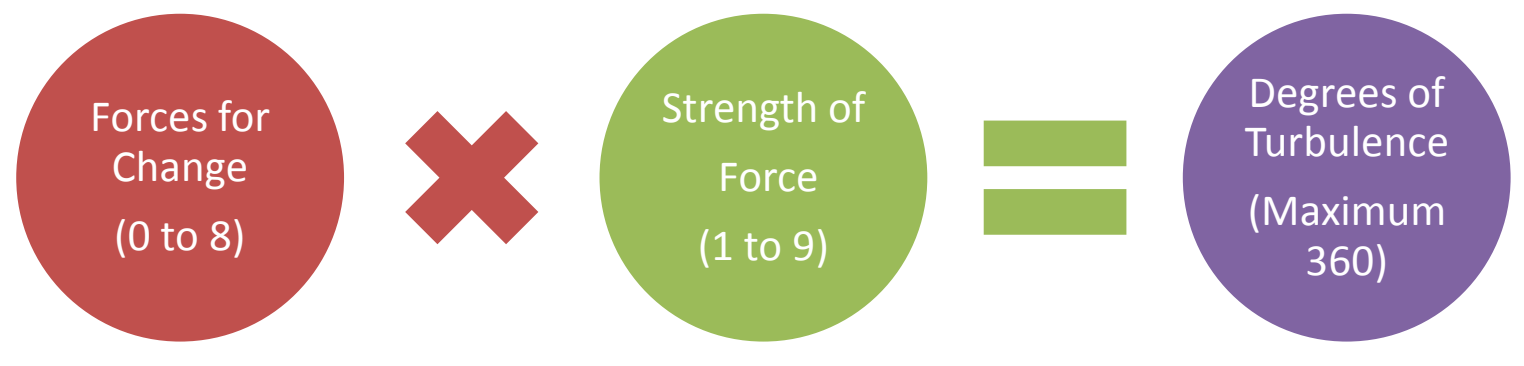

\section{Step Four: Interpretation - What does it mean?}

The Degrees of Turbulence factor should then be assessed against the interpretation below.

- $\quad$ Between 0 and 72 - Changes in the environment are barely influencing your organization - there is time to plan and implement your business decisions. Operations are being conducted in a very stable industry, perhaps under long term contracts.

- $\quad$ Between 73 and 144 - The SMEs in this category are able to adjust and change similar to the process described in the newer models for organizational change - using the strengths of leadership and inherent flexibility of SMEs to do so. 
- Between 145 and 216 - This is not unusual for SMEs as they have limited market power and are very subject to the forces for change - while using leadership and flexibility, limited resources and lack of market power are often evidenced.

- $\quad$ Between 217 and $\mathbf{2 8 8}$ - This SME is experiencing a very high degree of change from external forces and it probably seems that one change is just dealt with before another requires leadership skills, available resources and another adjustment to the structure of the organization.

- $\quad$ Between 288 and 360 - You are spinning - 360 degrees would mean that your SME is barely controllable by management direction.

SMEs that identify high degrees of turbulence would be well advised to secure stable forms of financing, have flexibility in their operating structures, and consider diversification for risk reduction. Conversely firms that have low degrees of turbulence could engage in riskier markets, take on short-term financing and make longer term commitments in their operating structures. The owners/managers of SMEs as leaders or their organization need to have a clear understanding of their operating environment in order to respond to the forces for change either proactively according to the business and/or strategic plan or reactively if the situation has not been considered in the planning process. Not all organizations have capabilities in environmental surveillance (Joyce \& Woods, 2003) and the proposed Degrees of Turbulence model should assist SMEs in building this capability.

The development of a new tool to aid SMEs in the assessment of their external relationships has the potential to aid in the survival and growth of SMEs in the current business environment. SMEs have limited or no control over the external environment (Curran \& Blackburn, 2001) but must meet the forces for change if they are to survive and grow. The value of a model in understanding a complex reality, combined with the lack of emphasis on strategic planning in SMEs, has led to the development of this proposed new tool. The development of tools specifically for the SME environment should encourage engagement in strategic planning within SMEs and thus assist more of them to survive and grow to meet the expectations of the their owners, stakeholders and respective jurisdictions.

\section{AUTHOR INFORMATION}

Dr. Heather C. Banham, CGA earned her Doctor of Business Administration degree at the University of Southern Queensland, Australia and holds her professional accounting designation as a CGA (Certified General Accountant) in Canada. She is currently the Dean of the Okanagan School of Business at Okanagan College in British Columbia, Canada and her background includes working with public and private organizations in accounting and management positions. Current research interests include organizational development and change, small and medium enterprises (SMEs) and international student success.

\section{REFERENCES}

1. Asia Pacific Economic Cooperation (2002). The APEC Working Committee Retrieved from http://www.apecsec.org.sg and http://www.guidetoeconomy.org

2. Banham, H.C.( 2005). Organizational change in small and medium enterprises: A regional study. Retrieved from http://eprints.usq.edu.au/663/1/Banham_02whole DBADissertationAugust2005.pdf

3. Beaver, G. (2007). The strategy payoff for smaller enterprises, The Journal of Business Strategy, 28(1), 1119.

4. Burke, W.W. (2002), Organization Change Theory and Practice, Sage Publications, Thousand Oaks, California

5. Canadian Federation of Independent Business, Canadian Manufacturers and Exporters, RBC Financial Group (2002), The Path to Prosperity: Canada's small- and medium-sized enterprises, [Online], www.cfib.ca/research/reports/pdf/sme 2002 e.pdf [Accessed 06 November 2002]

6. Cecora, J. (2000) 'Entrepreneurs and SMEs in Regional economies: Policy Issues for Sustainable Development in a Globalizing Economy', International Review of Sociology, Vol. 10 No. 1 pp.83-100

7. Chan, S.Y. \& Foster, M.J,( 2001) 'Strategy formulation in small business: the Hong Kong Experience', International Small Business Journal, Vol. 19, Issue 3, pp 56-71 
8. Chetty, S. \& Campbell-Hunt, C., (2003), 'Explosive international growth and problems of success amongst sall to medium-sized firms' International Small Business Journal, London, Vol. 21 Issue 1 pp. 5-20

9. Curran, J. \& Blackburn R.A. (2001), Researching the Small Enterprise, Sage Publications, London

10. Delaney, J.T. \& Huselid, M.A. (1996), 'The impact of human resource management practices on perceptions of Organizational Performance', Academy of Management Journal, Briarcliff Manor, Vol. 39, Issue 4, pp.949-970

11. Dawson, P. (2001), 'Organizational Change' in Management and Organizational Behaviour, Eds. R. Wiesner and B. Millett, John Wiley and Sons, Australia

12. Economic Development Commission of the Central Okanagan (2002) [Online] Available: www.edcord.com/economic/sectors.htm [Accessed 06 October 2002]

13. Freel, M.S. (2000), 'Barriers to product innovation in small manufacturing firms', International Small Business Journal, London, Vol. 18 Issue 2 pp.60-80

14. Fuller, T. (2003), 'If you wanted to know the future of small business what questions would you ask?' Futures 35 (IPC Science and Technology Press in Co-operation with the Institute for the Future), vol. 35 Iss. 4, pp.305-321

15. Gadenne, D. (1998), 'Critical Success Factors for Small Business: An inter-industry comparison', International Small Business Journal, London, Vol. 17 Issue 1 pp.36-56

16. Hodges, H.E.\& Kent, T.W. (2007), 'Impact of Planning and Control Sophistication in Small Business, Journal of Small Business Strategy, Peoria, Fall2006/Winter2007, Vol 17 Iss 2 pp. 75-88

17. Huang X, Soutar, G.N. \& Brown, A. ( 2002), 'New product development processes in small and mediumsized enterprises: Some Australian evidence', Journal of Small Business Management, Milwaukee, January 2002

18. Joyce, P. \& Woods, A. (2003), Managing for growth: decision making, planning, and making changes, Journal of Small Business and Enterprise Development, 10 (2) 2003 pp. 144-151

19. McAdam, R. (2000), 'The implementation of reengineering in SMEs: A grounded study' International Small Business Journal, London, Jul-Sep 2000

20. McAdam, R. \& Armstrong, G. (2001), 'A symbiosis of quality and innovation in SMEs: A multiple case study analysis' Managerial Auditing Journal, Bradford, Vol. 16, Issue 7, pp.394-401

21. McAdam, R. (2002), 'Large-scale innovation -- reengineering methodology in SMEs: Positivistic and phenomenological approaches' International Small Business Journal, London, Feb. 2002

22. MacDougall, S.L., \& Pike, R.H., 2004, 'Partial Abandonment by SMEs Investing in Advanced Manufacturing Technology: Some Qualitative Evidence' Journal of Small Business and Entrepreneurship, Regina, Canada, Vol. 17, No. 2, pp. 79-92

23. McDonald, J \& Wiesner, R. (1997), Organizational Change and HRM Strategies in SME's, University of Southern Queensland, Toowoomba Queensland

24. Meers, K.A., \& Robertson, C. (2007), 'Strategic Planning Practices in Profitable Small Firms in the United States', The Business Review, Cambridge, Hollywood, Summer 2007 Vol 7 Iss1; pp. 302-308

25. Miller, D. \& Toulouse, J.M. (1986), 'Chief Executive Personality and Corporate Strategy and Structure in Small Firms' Management Science, Vol. 32, No. 11, pp. 1389-1409

26. National Quality Institute (2009), 'The Best 12 Questions to Ask in Hard Times', www.nqi.ca [Accessed February 23, 2009]

27. Small Business Roundtable. (2006). Report to government, 2006. Victoria, BC Retrieved from http://www.smallbusinessroundtable.ca/publications.htm\#2006

28. Small Business Roundtable. (2007). Report to government, 2006. Victoria, BC Retrieved from http://www.smallbusinessroundtable.ca/publications.htm\#2007

29. Todtling, F. \& Kaufmann, A. (2001) 'The Role of the Region for Innovation Activities of SMEs' Sage Publications, European Urban and Regional Studies 8 (3) pp. 203-215

30. Wang, C., Walker, E.A. \& Redmond, J. (2007) 'Explaining the Lack of Strategic Planning in SMEs: the Importance of Owner Motivation', International Journal of Organisatinal Behaviour, Vol. 12 (1), pp. 1-16

31. Woods, A. \& Joyce, P. (2003), 'Owner-Managers and the Practice of Strategic Management' International Small Business Journal, London 21 Issue 2: 181-195 DOI: 10.1177/02662424603021002003

32. Zeffane, R., (1996). 'Dynamics of strategic change: critical issues in fostering positive organizational change', Leadership and Organization Development Journal, Bradford Vol. 17, Issue 7, pp.36-43 


\section{NOTES}

